\title{
On the critical axial forces of upheaval buckling for imperfect submarine pipelines
}

\author{
Leige $\mathrm{Xu}^{\mathrm{a}, \mathrm{b}}$, Mian Lin ${ }^{\mathrm{b}, \mathrm{c}, *}$ \\ ${ }^{a}$ School of Civil Engineering and Transportation, North China University of Water Resources and Electric Power, Zhengzhou, China \\ ${ }^{\mathrm{b}}$ Institute of Mechanics, Chinese Academy of Sciences, Beijing, China \\ ${ }^{\mathrm{c}}$ School of Engineering Science, University of Chinese Academy of Sciences, Beijing, China
}

\section{A R T I C L E I N F O}

\section{Article history:}

Received 1 August 2016

Revised 1 June 2017

Accepted 9 June 2017

Available online 20 June 2017

\section{Keywords:}

Submarine pipeline

The VFIFE method

Dimensional analysis

Dimensionless imperfection length

Upheaval buckling

\begin{abstract}
A B S T R A C T
For pipelines with vertical imperfection, upheaval buckling may occur if the axial compressive force reaches the critical axial force of upheaval buckling. The critical axial force is sensitive to the pipeline imperfection and previous researchers have suggested that there is no universal analytical solutions for the critical axial force of upheaval buckling for imperfect pipelines. However with theory of dimensional analysis, it was proved that there should be a general form of the approximation formulas of the critical axial force, although the coefficients in the formulas are different for different imperfection shapes. And most recently, Zeng et al. proposed approximation formulas of the critical axial force accounting for the Out-of-Straightness (OOS) of the imperfection, while they haven't considered the influence of the imperfection size. In this paper, effect of the imperfection size on the critical axial force was proved significant even when the OOS and shape of the imperfection are determined. To account for this size effect, a parameter named the dimensionless imperfection length is proposed based on theory of dimensional analysis. This parameter combined the effects of the imperfection length, the vertical distributed force and the pipeline bending stiffness. A formula of the critical axial force, covering the newly proposed parameter and the OOS of the imperfection, is derived, and coefficients in the formula are determined with numerical results from the Vector Form Intrinsic Finite Element (VFIFE) simulations. Notably, the coefficients in the formulas are not constants but assumed to change with the OOS and the dimensionless imperfection length to account for the geometric nonlinearity of the initially curved pipeline. The proposed formulas are proved more accurate than previous ones and applicable for pipes with different cross-sectional properties and different buried conditions. They are also suggested within the error range of $\pm 5 \%$ in the dimensionless scope of the OOS from 0.001 to 0.01 and the dimensionless imperfection length from 0.89 to 4.95 .
\end{abstract}

(c) 2017 Elsevier Ltd. All rights reserved.

\section{Introduction}

When a pipeline is with vertical imperfection, it may buckle vertically once the axial compressive force is larger than a value called the critical axial force of upheaval buckling. The buckling behavior may eventuate in local buckling or rupture of the pipe wall and then cause severe economic losses and environmental damage [1-3]. Fig. 1a and b show a buried pipeline with an initial structural imperfection and an unburied pipeline laid on an uneven seabed, respectively. They are both at the risk of upheaval buckling if the pressure or temperature of the internal flow is high enough. Because the upheaval buckling happens only when the axial

\footnotetext{
* Corresponding author at: Institute of Mechanics, Chinese Academy of Sciences, Beijing, China.

E-mail address: linmian@imech.ac.cn (M. Lin).
}

compressive force of the pipeline reaches the critical value, designers could prevent its happening by keeping the axial force smaller than the critical axial force of upheaval buckling. Therefore, one of the key problem in pipeline design is to predict the critical axial force of upheaval buckling with a great precision.

Many researches have been conducted to study the critical axial forces of upheaval bcukling for pipelines with initial imperfections. Tvergaard [4] proposed governing equation and gave analytical solutions for upheaval buckling of pipelines with periodic sinusoidal imperfections. In the analysis, the buckling mode is assumed to be growth of the initial imperfection. Yun and Kyriakides [5] studied the upheaval buckling of buried pipelines through a large deflection extensional beam nonlinear formulation. They found the critical axial forces are sensitive to the pipeline imperfection. Richards [6] studied the influence of imperfection shape on upheaval buckling behavior and suggested that this influence is 
(a)

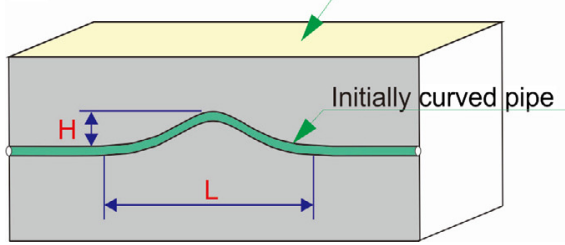

(b)

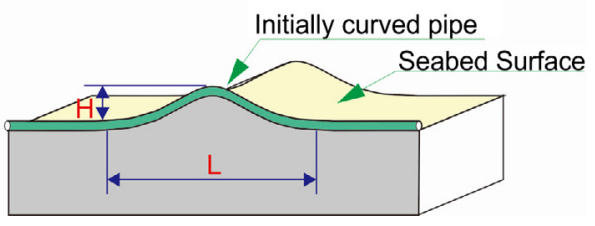

Fig. 1. Schematic diagram of (a) a buried pipeline, and (b) an unburied pipeline, with initial upheaval structural imperfections.

significant. Croll [1,7] deduced analytical expressions of the upper and lower bounds of the critical axial force, whilst the length and height of the imperfection are separating in their equations. Maltby and Calladine [8,9] and Taylor et al. [10-13] proposed analytical solutions of the critical axial forces of upheaval buckling and suggested the great influence of the imperfection length $L$ and hight $H$ on the ciritical axial force. Also, they assumed that the buckling mode of a pipeline is the growth of the initial imperfection. Karampour et al. [14] proposed a tabulated analytical solution in terms of the governing characteristic equations based on a long heavy elastic beam resting on a rigid foundation. Critical axial forces can be obtained by numerically solving the characteristic equations, while only characteristic equations for several typical imperfection shapes have been obtained. Actually, Zhang and Duan [15] has suggested that although there have been already some formulas to calculate critical axial force for some particular initial imperfection shapes, there is no universal analytical solution to express the effects of initial imperfection on the critical axial force. The reason is that the critical axial force is strictly related to the imperfection shape and until now researchers could only find out analytical solutions for several imperfection shapes which could be represented by some common functions. Wang et al. [16] conducted perturbation analysis for upheaval buckling of imperfect pipeline. They also pointed out that since the upheaval buckling of submarine pipelines is an unstable nonlinear and localized problem, there is no universal analytical solution for this problem.

Nevertheless, Palmer et al. [17] proposed that there should be a general form of the formulas for the critical force of upheaval buckling. They pointed out that the general form of the formulas would keep unchanging for different imperfection shapes, although the coefficients in the formulas could be different for different imperfection shapes. This means that if the form of the formulas is obtained with dimensional analysis, coefficients in the formulas can be fitted with numerical or experimental data for pipelines with different imperfections. Most recently, with the theory of dimensional analysis and finite element analysis, Zeng et al. [18] studied the influences of the Out-of-straightness (OOS) and the imperfection shape and proposed approximation formulas of the critical axial force. Also, they suggested that the forms of the critical axial force formulas for different imperfection shapes are the same. The formulas of Zeng et al. [18] have the form of Eq. (1).

$P_{\mathrm{cr}}=\mathrm{C}\left(q^{2} E I\right)^{\frac{1}{3}}\left(\frac{H}{L}\right)^{\beta}$

where $P_{\mathrm{cr}}$ is the critical axial force; $H$ and $L$ are the height and length of the imperfection, respectively; $q$ is the vertical distributed force; $E I$ is the bending stiffness of the pipeline; $C$ and $\beta$ are constants.

The above equation includes the influence of the imperfection in the form of the OOS H/L and indicates that $P_{\mathrm{cr}}$ will keep unchanging when $E I, q$ as well as the shape and the OOS $H / L$ of the imperfection is determined. The above equation considers the influence of the Out-of-straightness $H / L$, which is the relative height of the imperfection. However, it couldn't reflect the influence of the "size" of an imperfection. For example, following Eq. (1), if EI, $q$ and shape of the imperfection are determined, a pipeline with a large imperfection (e.g., $L=100 \mathrm{~m}$ and $H=0.1 \mathrm{~m}$ ) and a pipeline with a small imperfection (e.g., $L=10 \mathrm{~m}$ and $H=0.01 \mathrm{~m}$ ) will have the same critical axial force of upheaval buckling, since the two imperfections have the same OOS $=0.001$. However in our study, it is found that for a typical imperfection shape, even when the bending stiffness $E I$, the vertical distributed load $q$ and the OOS $H / L$ are determined, the imperfection size could influence the critical axial force of upheaval buckling. Therefore, this study will focus on this size effect and deriving more general formulas for the critical axial forces of upheaval buckling.

In this paper, numerical simulations are conducted using the Vector Form Intrinsic Finite Element (VFIFE) method. The results are compared with those of conventional Finite Element Method (FEM) and effect of the imperfection size is discussed. Subsequently, a new parameter named dimensionless imperfection length is proposed by using theory of dimensional analysis. Approximation formula of the critical axial forces is derived and it covers the dimensionless imperfection length and the OOS. Coefficients in the proposed formula are fitted with numerical results for pipelines with three imperfection shapes. Moreover, the proposed formulas are compared with numerical results of pipelines with different cross-sectional properties and different buried conditions. And finally, the dimensionless application scopes of the proposed formulas are determined.

\section{Numerical method and analysis}

In this paper, the Vector Form Intrinsic Finite Element (VFIFE or V-5) method is used to conduct numerical simulations. The VFIFE method was proposed by Shih et al. [19] and Ting et al. [20,21]. It is not only a vector mechanics-based mathematical calculation method for structures with large deformation, but also accurate for small deformation problem [22]. In recent years, it was used in analysis of pipelines and suggested to be a useful tool.

Yuan et al. [22] studied the damage of pipelines caused by submarine landslides or debris flows using the VFIFE plane beam element. Three-dimensional VFIFE beam element was used to simulate submarine pipelines by $\mathrm{Xu}$ and Lin [23]. They worked out a FORTRAN procedure with the VFIFE method and proved the VFIFE method is as accurate as traditional FEM in simulating of free-spanning pipelines. In the procedure, the VFIFE method was integrated with the UWAPIPE model $[24,25]$ to consider the complicated pipe-soil interaction. For simulation of long-distance pipelines, the computing amount is considerable. Therefore, $\mathrm{Xu}$ and Lin [26] proposed a high-efficiency Message Passing Interface (MPI) parallel scheme suitable for the VFIFE method and developed the MPI-parallel VFIFE procedure. Using the procedure, they simulated the configuration of a $10 \mathrm{~km}$ long-distance pipeline lying on a real irregular seabed and proved the VFIFE model is a useful tool for simulation of long-distance pipelines. To study the potential failure positions and plastic deformation of pipelines subjected to active faults, Liu et al. [27] developed the procedure by incorporating the VFIFE method with fiber element model. Furthermore, Xu 
and Lin [28] proposed a beam-shell coupling scheme based on the VFIFE method to simulate local buckling of long-distance pipelines crossing active faults. A MPI parallel procedure using the beamshell coupling scheme was also developed and numerical results shows that the procedure is both efficient and accurate for analysis of long-distance pipelines.

In the present research, the VFIFE procedure developed by $\mathrm{Xu}$ and Lin $[23,26]$ is used in the upheaval buckling simulation of pipelines. The foundation is assumed to be rigid and the pipeline is initially in contact with the foundation. For the simulations in this paper, the VFIFE method and the conventional FEM [15,18] are both effective tools, while the VFIFE method might be more promising in study of global buckling for long-distance pipelines because its advantages in integration with different pipe-soil interaction models [23,26-28] and its high efficient in MPI parallel computing $[26,28]$.

In this section, the three-dimensional VFIFE beam element is briefly introduced. Subsequently, pipelines with vertical imperfections are simulated using the VFIFE method. And the results are compared with traditional FEM results.

\subsection{The VFIFE method}

The VFIFE method models the analyzed domain composed of finite mass particles linked by elements. As shown in Fig. 2a, a pipeline is decomposed of finite mass particles linked by 3D beam elements. The mass of the pipeline is concentrated at the particles and the elements are weightless. Shape and position of a solid structure are described by tracing the particles' motions. Note that a mass particle is also called a node to conform to conventional FEM. In Fig. $2 \mathrm{~b}, t_{a}$ and $t_{i}$ are the starting and ending time of a movement, respectively. The time from $t_{a}$ to $t_{i}$ is discretized into a series of small time steps divided by $t_{b}, t_{c}, t_{d}, \ldots, t_{i}$.

In the VFIFE method, the following assumptions are made [22]: a) The deformation of the elements during each time step is so small that the hypothesis of small deformation in the mechanics of the material is always satisfied; and b) The material properties and structural dimensions of the structure do not change in each time step. For example, during the time step from $t_{\mathrm{a}}$ to $t_{\mathrm{b}}$, the material properties and structural dimensions are constant. This information is updated only after the time step $d t$ (at $t_{\mathrm{b}}$ ).

During one time step $t_{c} \leq t \leq t_{d}$, the state at $t_{c}$, instead of the starting state at $t_{a}$, is taken as the initial condition. Node movement is computed according to the Second Newton's Law as:

$\mathbf{M}_{\alpha} \frac{\mathrm{d}^{2} \mathbf{x}_{\alpha}}{\mathrm{d} t^{2}}(t)=\mathbf{P}_{\alpha}(t)+\mathbf{f}_{\alpha}(t) \quad(\alpha=1,2,3, \cdots, N)$

$\mathbf{I}_{\alpha} \frac{\mathrm{d}^{2} \theta_{\alpha}}{\mathrm{d} t^{2}}(t)=\mathbf{Q}_{\alpha}(t)+\mathbf{m}_{\alpha}(t) \quad(\alpha=1,2,3, \cdots, N)$

where $\alpha$ is the node number and $t$ is time; $\mathbf{M}_{\alpha}$ is the mass matrix; $\mathbf{x}_{\alpha}$ is the node position; $\mathbf{P}(t)$ is the external force; $\mathbf{f}(t)$ is the internal force; $\mathbf{I}_{\alpha}$ is the rotational inertia matrix; $\boldsymbol{\theta}_{\alpha}$ is the rotational vector;
$\mathbf{Q}_{\alpha}$ and $\mathbf{m}_{\alpha}$ are the external and the internal moments matrix, respectively. Eqs. (2) and (3) illustrate that the VFIFE method is a time-domain analysis method. Refer to Ting et al. [29] for details about calculating the mass matrix and the rotational inertia matrix.

The external forces in Eqs. (2) and (3) may be either node forces directly applied on the nodes or distributed force applied on the elements. The equivalent forces and moments of the distributed force can be determined according to the principles of static equilibrium.

The VFIFE method is a combination of the theory of particle dynamics and FEM. As shown in Fig. 2a, the nodes' motion is governed by the theory of particle dynamics as shown in Eqs. (2) and (3), whilst the interaction forces between neighboring nodes are calculated out using FEM. The node inner forces in Eqs. (2) and (3) are the summation of the forces from the linking elements.

Displacement of an element is composed of rigid motion and deformation of the element [30]. In the VFIFE method, the rigid element motion is eliminated with fictitious reversed movement and the element inner forces are directly calculated out with the element deformation. Details about calculating the inner forces of the VFIFE 3D beam element are introduced in Ting et al. [29]. In the VFIFE method, element deformation is obtained using the fictitious reversed element motion, the formulas of which is difficult to derive for high-order elements. As a result, only several types of low-order VFIFE elements have been proposed so far [19$21,29,31]$.

\subsection{Verification of the VFIFE method}

Zeng et al. [18] studied the buckling of imperfect pipelines using the software package ABAQUS. For the sake of comparison and assessing the accuracy of the proposed VFIFE method, the same pipeline used by Zeng et al. [18] is simulated in this section. Fig. 3a shows the analytical model of the studied pipeline system. This model is similar to the ones used by previous researchers $[11,15,18]$, who conducted analysis of pipeline upheaval buckling using FEM. In Fig. 4, the critical axial forces are compared to results in Zeng et al. [18]. The difference is small and the maximum relative difference is about $3 \%$. The VFIFE procedure is therefore suggested as accurate as the conventional FEM in analysis of pipeline upheaval buckling.

Sensitivity analysis has been carried out and the modeled pipeline length was proved to hardly influence the critical axial force of upheaval buckling but to greatly influence the post-buckling behavior. This is in accordance with the proposition of Zhu et al. [32] that the length of the modeled pipeline will not influence the critical condition of global buckling. Longer the modeled pipeline is, more dramatic the post-buckling behavior will be and more accurate it will be to identify the onset of upheaval buckling. Therefore, the overall length of the modeled pipeline is determined as $4 L$, where $L$ is the imperfection length.

The parameters of the studied pipeline are listed in Table 1 . The pipeline is initially in contact with the rigid foundation and all (a)

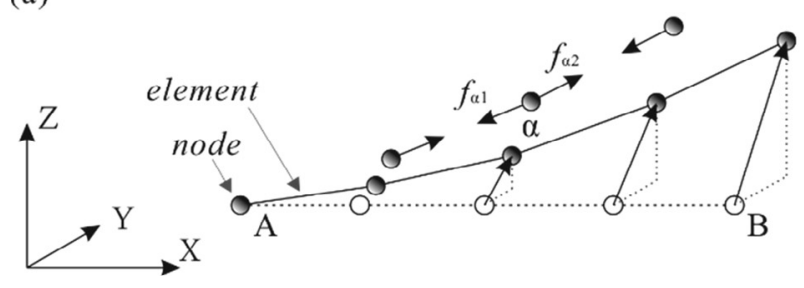

(b)

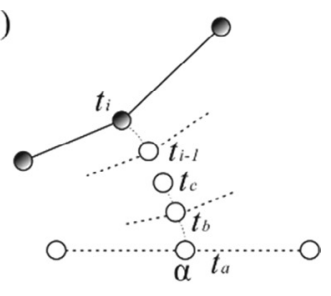

Fig. 2. (a) Structural discretization, and (b) time discretizations, of the VFIFE 3D beam element. 


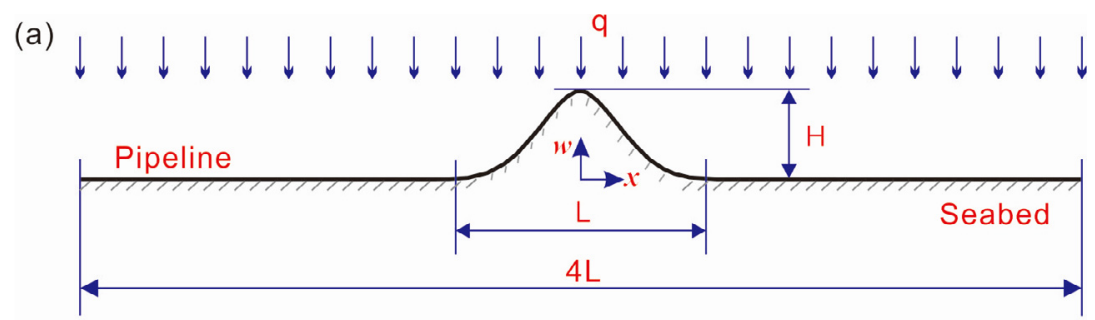

(b)

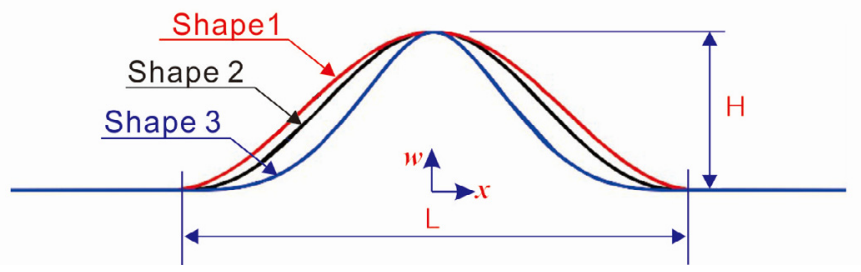

Fig. 3. (a) Analytical model of the studied pipeline system, and (b) diagram of three typical imperfection shapes.

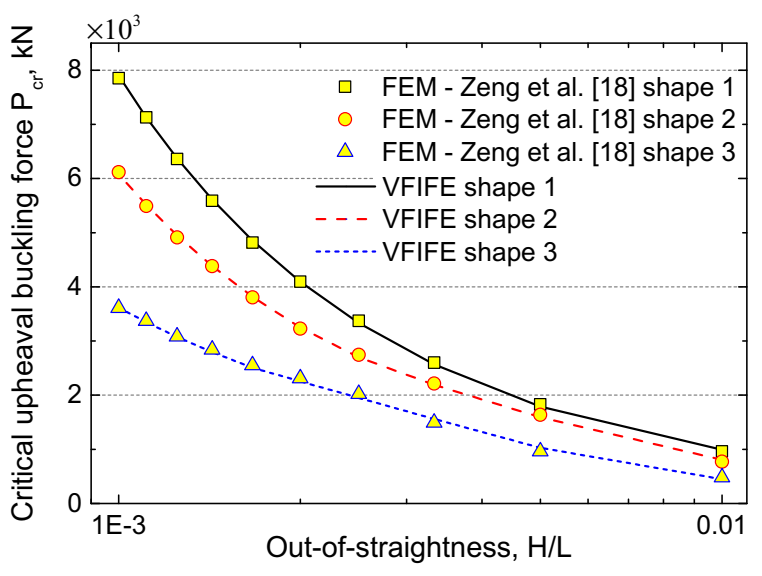

Fig. 4. Comparison between the critical axial forces using the VFIFE method and FEM [18]

Table 1

Parameters of the studied pipe.

\begin{tabular}{ll}
\hline Property & Value \\
\hline The outer diameter, $D(\mathrm{~mm})$ & 457 \\
The thickness of the steel pipe wall, $t(\mathrm{~mm})$ & 14.3 \\
The Young's modulus, $E(\mathrm{GPa})$ & 2.07 \\
The Poisson's ratio, $v$ & 0.3 \\
The equivalent cross-sectional moment of inertia, $I\left(\mathrm{~m}^{4}\right)$ & $4.88 \times 10^{-4}$ \\
The equivalent cross-sectional area, $A\left(\mathrm{~m}^{2}\right)$ & 0.0199 \\
The distribution load on pipelines, $q(\mathrm{~N} / \mathrm{m})$ & 1500 \\
The coefficient of thermal expansion, $C T E\left(/{ }^{\circ} \mathrm{C}\right)$ & $1.17 \times 10^{-5}$ \\
\hline
\end{tabular}

upheaval buckling behaviors happen within the elastic limit range. Since exact profile of the imperfection is not always available, three different imperfection shape functions $\left(f_{1} \sim f_{3}\right)$ are assumed to account for possible pipeline imperfections. The three functions have been adopted by previous researchers $[14,15,18]$ and are presented as follows.

Shape 1

$f_{1}(x)=\frac{H}{2}\left(1+\cos \left(\frac{2 \pi x}{L}\right)\right), \quad-\frac{L}{2} \leqslant x \leqslant \frac{L}{2}$
Shape 2

$f_{2}(x)= \begin{cases}H\left(\frac{8}{3}\left(\frac{2 x}{L}\right)^{2}+3 \frac{2 x}{L}+1\right)\left(1-\frac{2 x}{L}\right)^{3}, & 0 \leqslant x \leqslant \frac{L}{2} \\ H\left(\frac{8}{3}\left(\frac{2 x}{L}\right)^{2}-3 \frac{2 x}{L}+1\right)\left(1+\frac{2 x}{L}\right)^{3}, & -\frac{L}{2} \leqslant x<0\end{cases}$

Shape 3

$f_{3}(x)=\left\{\begin{array}{l}H\left(4 \frac{2 x}{L}+1\right)\left(\frac{2 x}{L}-1\right)^{4}, \quad 0 \leqslant x \leqslant \frac{L}{2} \\ -H\left(4 \frac{2 x}{L}-1\right)\left(\frac{2 x}{L}+1\right)^{4}, \quad-\frac{L}{2} \leqslant x<0\end{array}\right.$

where $H$ and $L$ are the height and length of the imperfection, respectively; $x$ is the coordinate in the longitudinal direction. The curves corresponding to the above functions are drawn in Fig. 3b. The function $f_{1}$ represents the fundamental buckling mode of a fix-ended column and previous researchers generally used shape 1 $[1,7,10,14,18]$. Shape 1 is the most moderate one among the three imperfection shapes, and shape 3 is more compacted than shape 2 .

To verify accuracy of the VFIFE procedure in pipeline buckling analysis, ten simulations with different OOS from 0.001 to 0.01 are performed for each imperfection shape. In each simulation, the imperfection length $L$ is $100 \mathrm{~m}$ and the modeled pipeline length is $400 \mathrm{~m}$. Both ends of the pipeline are fixed. The pipeline is uniformly discretized with element length of $1 \mathrm{~m}$ and the time increment is $d t=5.0 \times 10^{-5} \mathrm{~s}$. The loading time of the simulation is $300 \mathrm{~s}$, which is long enough to ensure the pipeline is in quasistatic condition before upheaval buckling occurs. In a structural analysis, the damping ratio can significantly influence the dynamic structural responses whilst hardly influences the quasi-static structural responses. Since a pipeline is in quasi-static condition before upheaval buckling, numerical results show that the damping ratio hardly influence the critical axial force of upheaval buckling. Larger damping ratio means more stable post-buckling responses of the pipeline. Therefore, a relatively larger structural damping ratio of $\zeta=0.1$ is used in this research to obtain more stable post-buckling behaviors of the pipelines.

In this paper, the critical axial force instead of the critical temperature of upheaval buckling is concerned. Therefore, the change of temperature is used to model the axial forces caused by change of both the temperature and the internal pressure following Zhang and Duan [15]. The internal flow temperature of the pipeline at initial time $t=0 \mathrm{~s}$ is $10^{\circ} \mathrm{C}$, and after a linear increase, it reaches $210^{\circ} \mathrm{C}$ at the ending of the loading process (at $t=300 \mathrm{~s}$ ). The coefficient of thermal expansion is $C T E=1.17 \times 10^{-5} /{ }^{\circ} \mathrm{C}$ as listed in Table 1 . 
Tomes et al. [33] indicated that for a given imperfection, the critical axial force required to buckle the pipeline is independent of the level of the axial seabed friction. Karampour et al. [14] also pointed out the effect of axial seabed friction on pipeline global buckling is only evident in post-buckling stage. In the present research, sensitivity analysis was carried out and the seabed friction was suggested hardly influence the critical axial force of upheaval buckling. Therefore, the friction ratio between the pipe and the foundation was set to a constant of zero.

When the imperfection height $H=0.1 \mathrm{~m}$, the vertical displacement curve and axial force curve of each pipeline's middle point are plotted in Fig. 5a and b, respectively. Since the axial compressive force and vertical displacement of the pipeline change suddenly when upheaval buckling occurs, onset of upheaval buckling is defined as the stage at which the sudden change appears. The
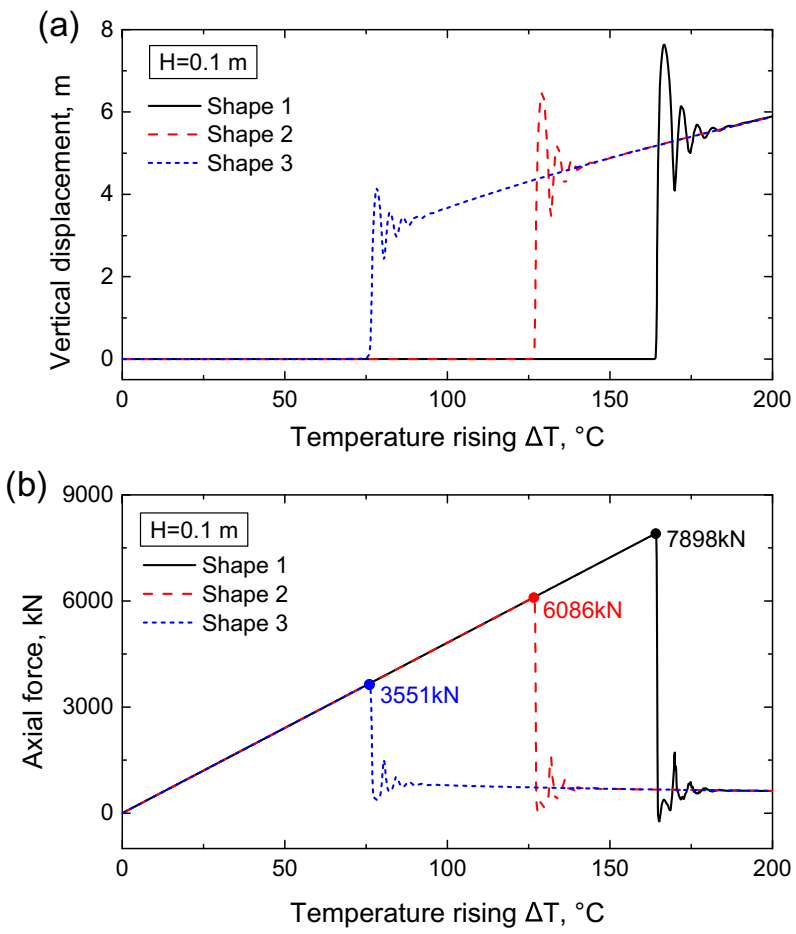

Fig. 5. Temperature rising versus (a) vertical displacement, and (b) axial force curves for cases with different imperfection shapes when $H=0.1 \mathrm{~m}$. corresponding axial force is called the critical axial force of upheaval buckling. As shown in Fig. 5, the critical axial forces are $7898 \mathrm{kN}, 6086 \mathrm{kN}$ and $3551 \mathrm{kN}$ for the pipelines with shape 1 , shape 2 and shape 3 , respectively. This indicates that the imperfection shape has a big influence on the critical axial force of upheaval buckling. And the more compacted the imperfection is, the lower the critical axial force will be.

The Von Mises stress and deformation of the pipeline for the case with shape 1 is plotted in Fig. 6 , where in order to show the vertical deformation, the vertical coordinates of the pipeline and the seabed are enlarged proportionally. Before upheaval buckling, the stress uniformly reaches at about $400 \mathrm{MPa}$ when temperature rising $\Delta T$ reaches $164^{\circ} \mathrm{C}$. After upheaval buckling, the stress in pipeline far away from the imperfection has a big decrease, while the stress in the imperfection region increases dramatically because of the severe pipeline deformation.
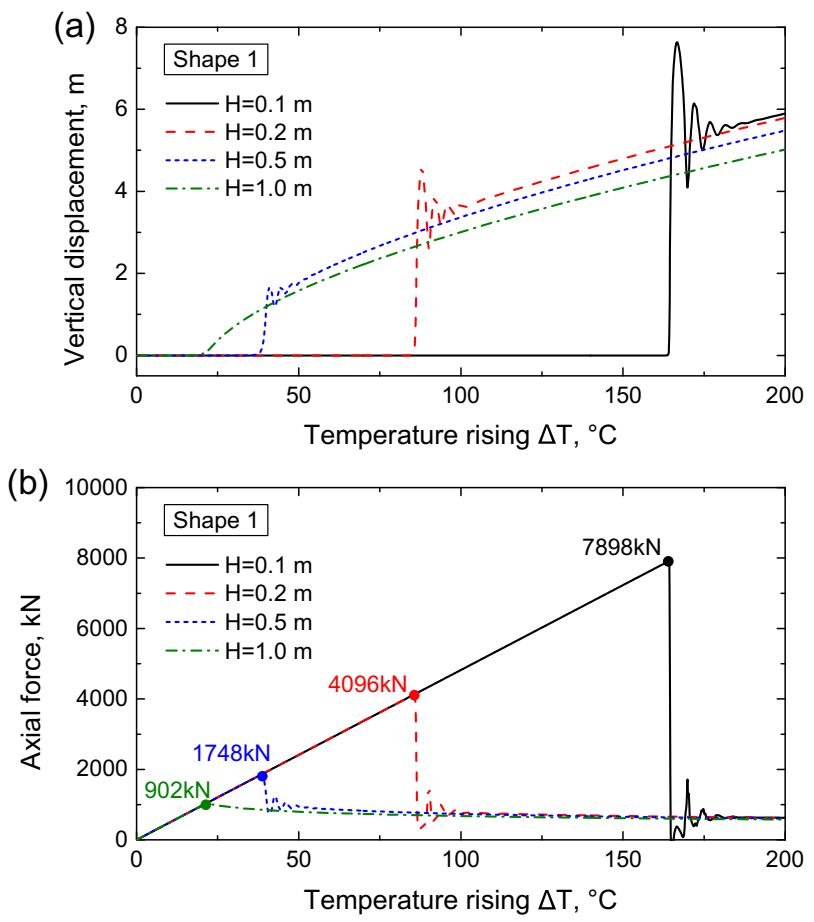

Fig. 7. Temperature rising versus (a) vertical displacement, and (b) axial force curves for cases with different imperfection heights (shape 1).

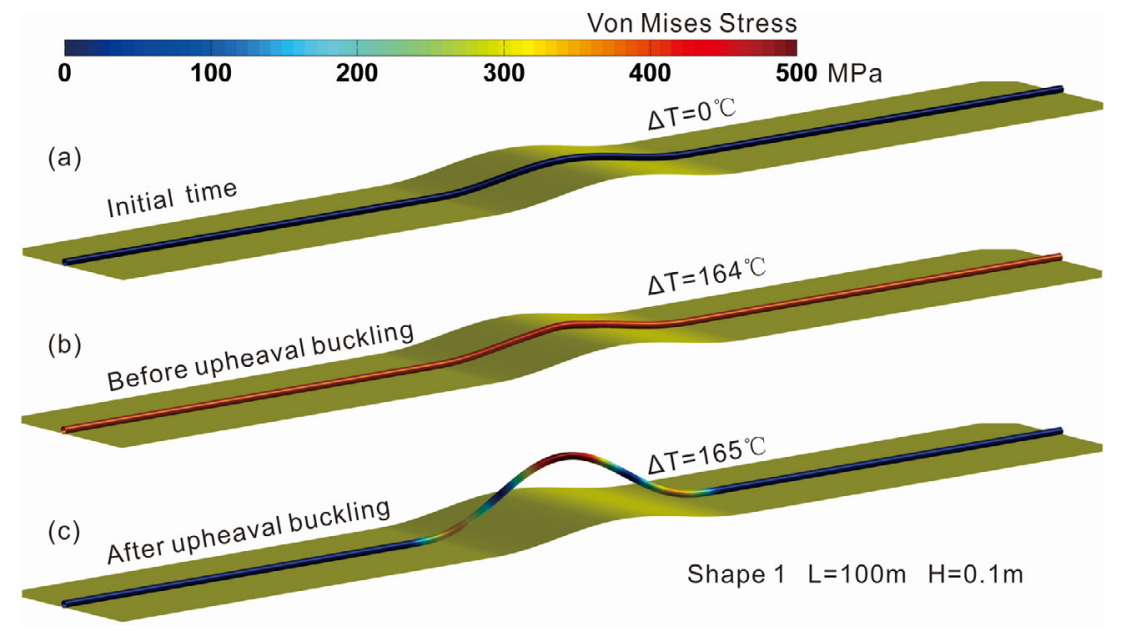

Fig. 6. The typical Von Mises stress and deformation contour plot (shape $1, H=0.1 \mathrm{~m}, L=100 \mathrm{~m}$ ). 
As shown in Fig. 7, as the imperfection height increases, not only the critical axial force decreases, but also the upheaval buckling occurs more moderately. When the imperfection height $H=1.0 \mathrm{~m}$, the stress and deformation of the pipeline is shown in Fig. 8. After upheaval buckling, the maximum Von Mises stress and deformation of the pipeline increase moderately with the temperature rising. This is different with what shown in Fig. 6, where the pipeline has a sudden deformation when upheaval buckling occurs.

\section{Dimensional analysis}

Based on the Euler buckling theory and previous researches on pipeline upheaval buckling [10,17], Zeng et al. [18] indicates that the critical axial force $P_{\mathrm{cr}}$ is related to $E I, q$ and $H / L$ and will keep unchanging when the above parameters are determined. However, the approximation formulas of Zeng et al. [18] haven't included the influence of the imperfection size on the critical axial force. Using dimensional analysis in a physics problem requires careful selection of fundamental quantities so that no key quantities is missed. In this paper, the critical axial force is determined as function of $E I$, $q, H$ and $L$ :

$P_{\text {cr }}=f(E I, q, H, L)$

In Eq. (7), dimensions are $\left[P_{\mathrm{cr}}\right]=F,[E I]=F L^{2},[q]=F / L,[H]=L$ and $[L]=L$. There are 5 physical quantities and 2 independent dimensions ( $F$ and $L$ ), so there must be 3 independent dimensionless quantities according to the Buckingham's Pi-theorem [34].

The Euler's formula for critical axial force of buckling of a compressed straight column is $\alpha\left(E I / L^{2}\right)$, where $\alpha$ is determined with the ends' constrains of the column. For the present problem, the critical axial force is different with but relative to that of a compressed straight column. Therefore in this paper, the critical force $P_{\mathrm{cr}}$ of the initially curved pipeline is normalized with the critical axial force of buckling of a compressed straight column as shown in Eq. (8).

$\bar{P}_{\mathrm{cr}}=\frac{P_{\mathrm{cr}}}{E I / L^{2}}=\frac{P_{\mathrm{cr}} L^{2}}{E I}$
Eq. (8) represents the ratio between the critical forces of the studied imperfect pipeline and a compressed straight column. Following previous researches $[15,18]$, another dimensionless quantity is defined as the OOS $H / L$. For an initially imperfect pipeline, the critical axial force is influenced not only by the relative height (OOS, $H / L$ ) of the imperfection, but also by the size of the imperfection. Normalize the imperfection length $L$ with $E I$ and $q$, the third dimensionless quantity is obtained as

$\bar{L}=L\left(\frac{q}{E I}\right)^{\frac{1}{3}}$

The above quantity $\bar{L}$ is named the dimensionless imperfection length and has two physical meanings. On one hand, the dimensionless imperfection length is the relative size of the imperfection with respect to the pipeline stiffness and the vertical distributed load. On the other hand, as shown in Eq. (10), qL is a stabilizing factor representing the vertical force applied on the imperfect pipeline and $E I / L^{2}$ represents the critical force of a compressed straight column. Therefore, the dimensionless imperfection length could also represent the relative vertical force applied on the imperfect pipeline.

$\bar{L}=\sqrt[3]{\frac{q L}{E I / L^{2}}}$

According to the Buckingham's Pi-theorem[34], the above three dimensionless independent quantities, namely the critical axial force $\bar{P}_{\mathrm{cr}}$, the OOS $H / L$ and the dimensionless imperfection length $\bar{L}$, can form definite relationship that reflect the substance of the problem,

$\bar{P}_{\mathrm{cr}}=f\left(\bar{L}, \frac{H}{L}\right)$

For imperfection with different shapes, previous researchers $[17,18]$ suggested that there is a general form of the formulas of the critical force of upheaval buckling. Tan [34] suggested that when processing numerical results, independent variables can

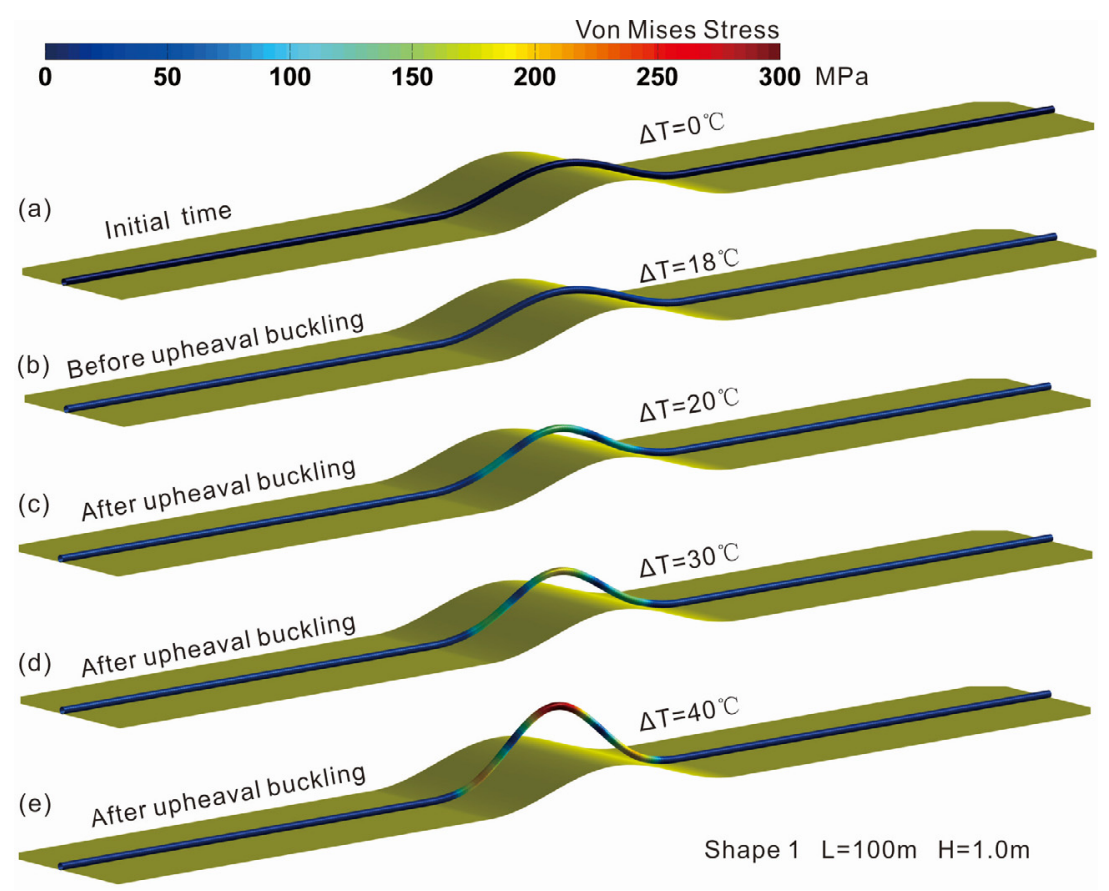

Fig. 8. The typical Von Mises stress and deformation contour plot (shape $1, H=1 \mathrm{~m}, L=100 \mathrm{~m}$ ). 
divide into different application ranges and a power formula can be adopted in each application range. Therefore, Eq. (11) is assumed to be the following function.

$\bar{P}_{\mathrm{cr}}=\mathrm{C} \bar{L}^{a}\left(\frac{H}{L}\right)^{b}$.

where C, $a$ and $b$ are parameters which could be fitted with numerical results. Substitute the dimensionless critical axial force Eq. (8) and the dimensionless imperfection length Eq. (9) into Eq. (1), and then Eq. (13) is obtained.

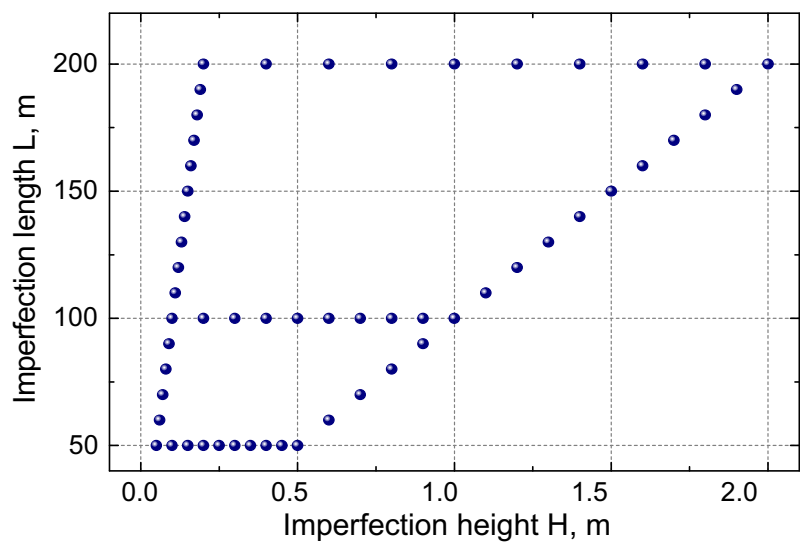

Fig. 9. The imperfection length and height for the studied cases.
$\bar{P}_{\mathrm{cr}}=\mathrm{C} \bar{L}^{2}\left(\frac{H}{L}\right)^{\beta}$

The above equation indicates that the formula of Zeng et al. [18] (Eq. (1)) is a typical case of Eq. (12) with the coefficient $a=2$. As indicated by previous researchers $[17,18]$, the imperfection shape only affects the coefficients of the critical axial force formulas, so that the coefficients in Eq. (12) is unique for a particular imperfection shape. This implies that if the imperfection shape is determined, this function can be determined. And if this function is determined, the critical axial force formula of a pipeline with a particular shape imperfection can be determined[18]. However, Eq. (13) assumes the coefficient $a$ is constant and doesn't change with imperfection shape, and this may introduce some errors.

Assuming that $Y=\lg \bar{P}_{\mathrm{cr}}, X_{1}=\lg \bar{L}, X_{2}=\lg (H / L)$, Eq. (12) transforms into the following form.

$Y=\lg C+a X_{1}+b X_{2}$

For a typical combination of dimensionless quantities in a small dimensionless scope, $a$ and $b$ in Eqs. (12) and (14) can be assumed to be constant and correspondingly, the above equation is a linear function among $Y, X_{1}$ and $X_{2}$. However, since upheaval buckling of imperfect pipeline is a geometric nonlinear problem, variation of $a$ and $b$ with the dimensionless quantities should be considered if a large application scope of the formula is desired. In this study coefficients $a$ and $b$ are assumed to change with $X_{1}$ and $X_{2}$, and to be linear function of $X_{1}$ and $X_{2}$.

$a=a_{0}+a_{1} X_{1}+a_{2} X_{2}$

Table 2

Critical axial force of upheaval buckling for cases with different OOS (unit $=\mathrm{kN}$ ).

\begin{tabular}{|c|c|c|c|c|c|c|c|c|c|}
\hline \multirow[t]{2}{*}{ oos } & \multicolumn{3}{|l|}{ Shape 1} & \multicolumn{3}{|l|}{ Shape 2} & \multicolumn{3}{|l|}{ Shape 3} \\
\hline & $L=50 \mathrm{~m}$ & $L=100 \mathrm{~m}$ & $L=200 \mathrm{~m}$ & $L=50 \mathrm{~m}$ & $L=100 \mathrm{~m}$ & $L=200 \mathrm{~m}$ & $L=50 \mathrm{~m}$ & $L=100 \mathrm{~m}$ & $L=200 \mathrm{~m}$ \\
\hline 0.001 & 4789 & 7898 & 15315 & 4158 & 6086 & 11422 & 3348 & 3551 & 4954 \\
\hline 0.002 & 2697 & 4096 & 7705 & 2340 & 3238 & 5778 & 1867 & 1965 & 2684 \\
\hline 0.003 & 1881 & 2813 & 5176 & 1626 & 2240 & 3903 & 1292 & 1352 & 1864 \\
\hline 0.004 & 1447 & 2153 & 3908 & 1248 & 1719 & 2963 & 991 & 1033 & 1426 \\
\hline 0.005 & 1176 & 1748 & 3147 & 1011 & 1395 & 2394 & 802 & 835 & 1155 \\
\hline 0.006 & 992 & 1472 & 2640 & 851 & 1173 & 2009 & 675 & 699 & 967 \\
\hline 0.007 & 856 & 1270 & 2274 & 734 & 1014 & 1734 & 582 & 602 & 837 \\
\hline 0.008 & 753 & 1120 & 1999 & 646 & 888 & 1522 & 513 & 534 & 735 \\
\hline 0.009 & 675 & 999 & 1782 & 578 & 796 & 1362 & 458 & 475 & 658 \\
\hline 0.01 & 602 & 902 & 1608 & 523 & 718 & 1227 & 413 & 427 & 590 \\
\hline
\end{tabular}

Table 3

Critical axial force of upheaval buckling for cases with different imperfection length (unit = kN).

\begin{tabular}{|c|c|c|c|c|c|c|}
\hline \multirow[t]{2}{*}{ Length $L(\mathrm{~m})$} & \multicolumn{3}{|c|}{$\mathrm{OOS} \mathrm{H} / \mathrm{L}=0.001$} & \multicolumn{3}{|c|}{$\mathrm{OOS} \mathrm{H} / \mathrm{L}=0.01$} \\
\hline & Shape 1 & Shape 2 & Shape 3 & Shape 1 & Shape 2 & Shape 3 \\
\hline 50 & 4789 & 4158 & 3348 & 602 & 523 & 413 \\
\hline 60 & 5286 & 4404 & 3295 & 653 & 550 & 401 \\
\hline 70 & 5874 & 4756 & 3310 & 712 & 585 & 399 \\
\hline 80 & 6520 & 5161 & 3378 & 771 & 625 & 405 \\
\hline 90 & 7199 & 5609 & 3455 & 834 & 669 & 416 \\
\hline 100 & 7898 & 6086 & 3551 & 902 & 718 & 427 \\
\hline 110 & 8612 & 6583 & 3662 & 970 & 767 & 442 \\
\hline 120 & 9339 & 7089 & 3783 & 1038 & 816 & 457 \\
\hline 130 & 10100 & 7643 & 3923 & 1106 & 864 & 472 \\
\hline 140 & 10834 & 8173 & 4058 & 1178 & 913 & 487 \\
\hline 150 & 11576 & 8704 & 4202 & 1246 & 966 & 507 \\
\hline 160 & 12318 & 9243 & 4347 & 1319 & 1019 & 521 \\
\hline 170 & 13067 & 9783 & 4491 & 1391 & 1072 & 541 \\
\hline 180 & 13812 & 10332 & 4646 & 1464 & 1121 & 556 \\
\hline 190 & 14564 & 10873 & 4800 & 1536 & 1174 & 575 \\
\hline 200 & 15315 & 11422 & 4954 & 1608 & 1227 & 590 \\
\hline
\end{tabular}


$b=\mathrm{b}_{0}+\mathrm{b}_{1} X_{1}+\mathrm{b}_{2} X_{2}$

where $a_{0}, a_{1}, a_{2}, \mathrm{~b}_{0}, \mathrm{~b}_{1}$ and $\mathrm{b}_{2}$ are constants. Substitute Eqs. (15) and (16) into Eq. (14) and then Eq. (17) is obtained.

$Y=\mathrm{C}_{0}+\mathrm{C}_{1} X_{1}+\mathrm{C}_{2} X_{2}+\mathrm{C}_{3} X_{1}^{2}+\mathrm{C}_{4} X_{2}^{2}+\mathrm{C}_{5} X_{1} X_{2}$

where $C_{0} \sim C_{5}$ are constants and have values of $C_{0}=\lg C, C_{1}=a_{0}$ $\mathrm{C}_{2}=\mathrm{b}_{0}, \mathrm{C}_{3}=a_{1}, \mathrm{C}_{4}=\mathrm{b}_{2}, \mathrm{C}_{5}=a_{2}+\mathrm{b}_{1}$. Mathematically, the above equation means that $Y$ is assumed to be quadratic function of $X_{1}$ and $X_{2}$. Substitute Eqs. (15) and (16) into Eq. (12) and transform the exponential terms, the following equation is obtained.

$\bar{P}_{\mathrm{cr}}=\mathrm{C} \bar{L}^{\mathrm{C}_{1}+\mathrm{C}_{3} \lg \bar{L}}\left(\frac{H}{L}\right)^{\mathrm{C}_{2}+\mathrm{C}_{4} \lg \left(\frac{H}{L}\right)+\mathrm{C}_{5} \lg \bar{L}}$
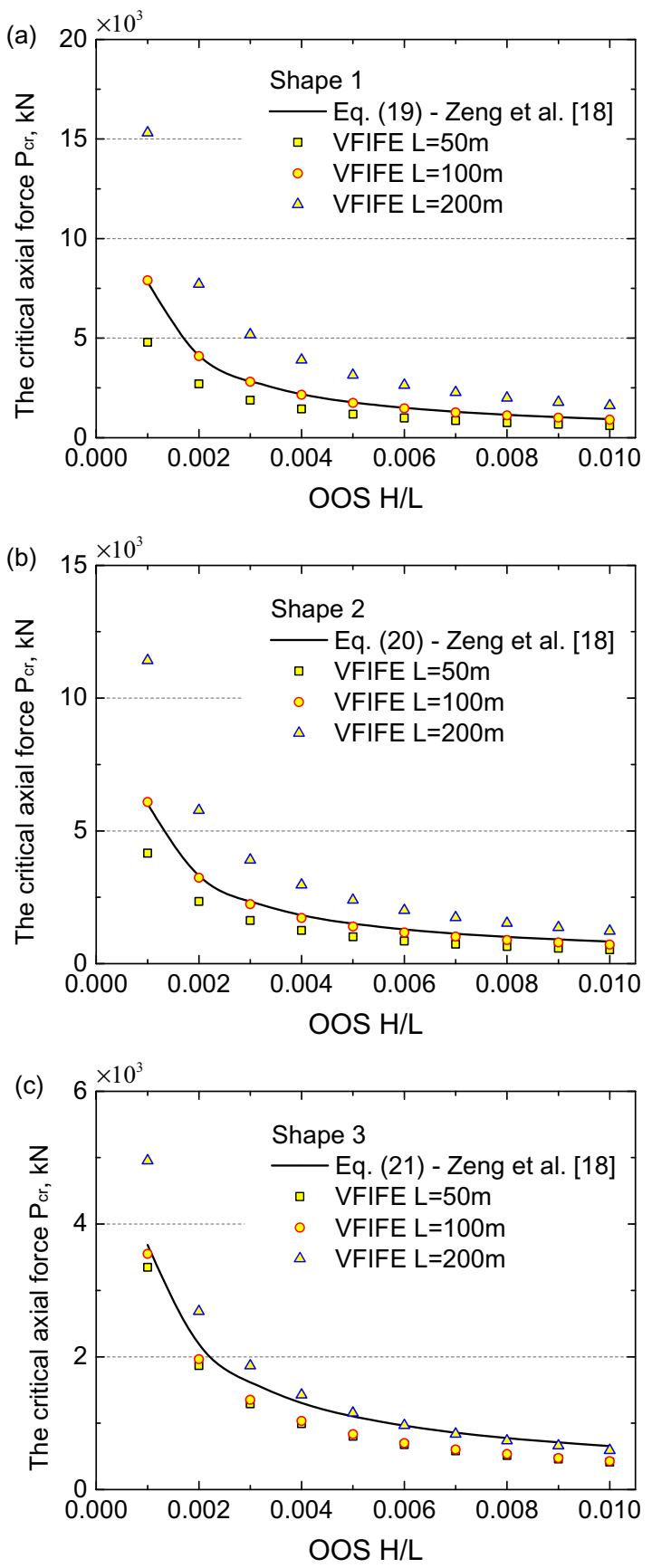

Fig. 10. The critical axial force versus the OOS for cases with different imperfection length: (a) shape 1 , (b) shape 2 , and (c) shape 3.
Apparently, Eq. (17) is the logarithmic form of Eq. (18). The coefficients $C_{0} \sim C_{5}$ will be fitted with the VFIFE results in this paper. Note that earliest researches $[1,7,10]$ gave critical axial force formulas of $P_{\mathrm{cr}} \propto(E I q / H)^{1 / 2}$ and Zeng proposed formulas in the form of Eq. (1). Compared with these previous formulas, Eq. (18) includes influence of not only the OOS, but also influence of the imperfection size and geometric nonlinearity by considering the dimensionless imperfection length and variation of the coefficients with the dimensionless quantities.

\section{Results and discussion}

\subsection{Effect of imperfection size}

In this study, totally 56 simulations are performed for pipelines with each imperfection shape. Each simulation is represented by a scatter point in Fig. 9. Parameters and the critical axial forces of all the cases are listed in Tables 2 and 3. For shape 1, shape 2 and shape 3, Zeng et al. [18] gave approximation formulas of the critical axial force of upheaval buckling as Eqs. (19)-(21), respectively.

$$
\begin{aligned}
& P_{\mathrm{cr} 1}^{\mathrm{Zeng}}=0.2204\left(q^{2} E I\right)^{1 / 3}\left(\frac{H}{L}\right)^{-0.9215} \\
& P_{\mathrm{cr} 2}^{\mathrm{Zeng}}=0.2581\left(q^{2} E I\right)^{1 / 3}\left(\frac{H}{L}\right)^{-0.8606} \\
& P_{\mathrm{cr} 3}^{\mathrm{Zeng}}=0.3407\left(q^{2} E I\right)\left(\frac{H}{L}\right)^{-0.7495}
\end{aligned}
$$
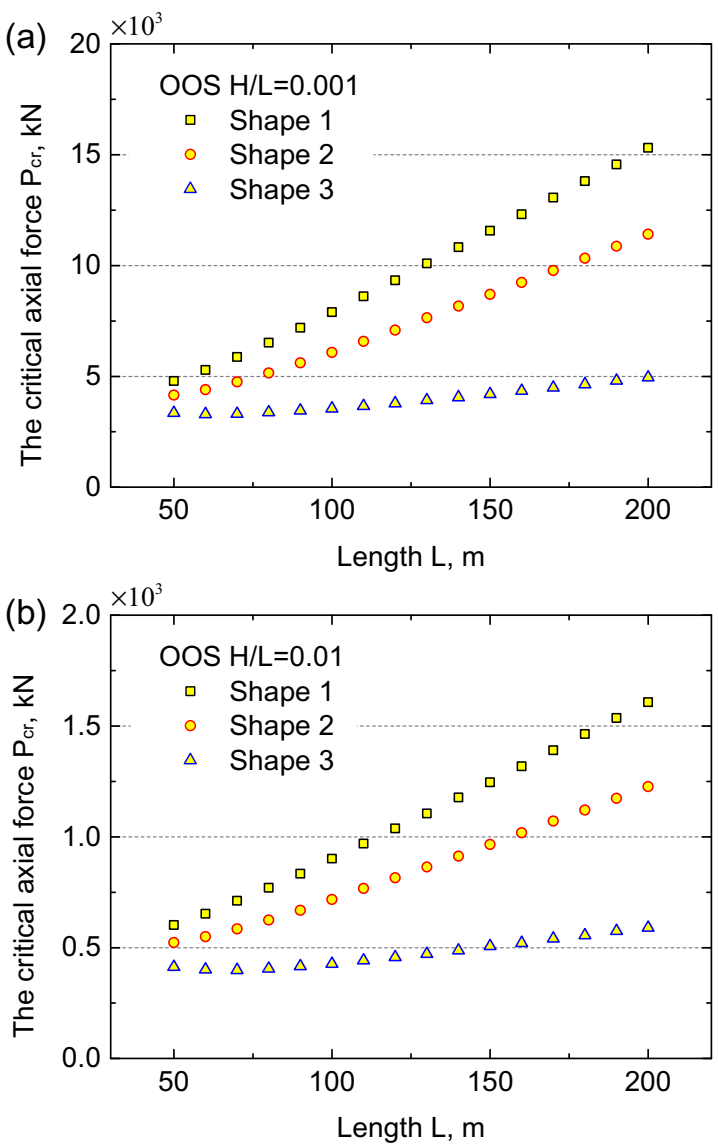

Fig. 11. The critical axial force versus the imperfection length when (a) the OOS is 0.001 , and (b) the OOS is 0.01 . 
When the imperfection length $L=50 \mathrm{~m}, 100 \mathrm{~m}$ and $200 \mathrm{~m}$, the critical axial forces are shown in Fig. 10, together with the predicted values of the approximation formulas of Zeng et al. [18]. When the OOS $H / L, q$ and $E I$ are constant, the approximation formulas of Zeng et al. [18] predicts constant critical axial force. This implies that the formulas of Zeng et al. [18] couldn't reflect the influence of imperfection size on the critical axial force. However, the results of the VFIFE analysis shows that the critical axial forces diverge significantly when the imperfection length is $50 \mathrm{~m}, 100 \mathrm{~m}$, and $200 \mathrm{~m}$ even when the OOS is constant. Actually, in all simulations of Zeng et al. [18], the imperfection length is $100 \mathrm{~m}$ and as a result, the size effect hasn't reflect in their study.

(a)

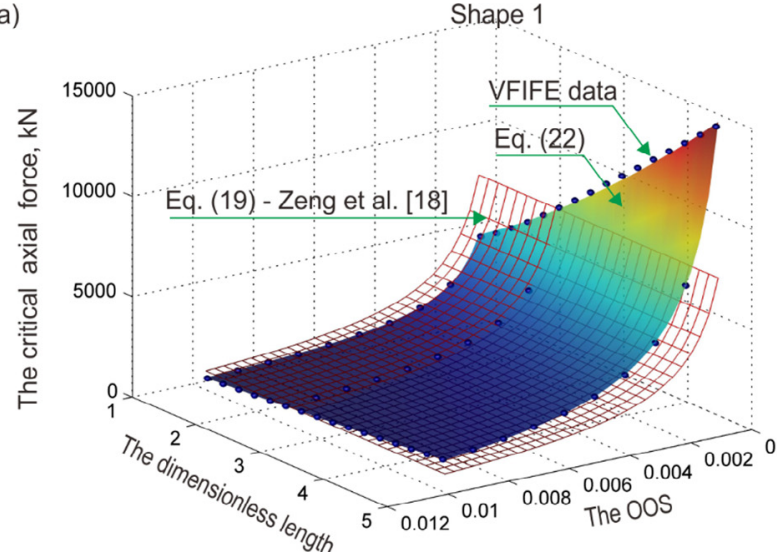

(b)

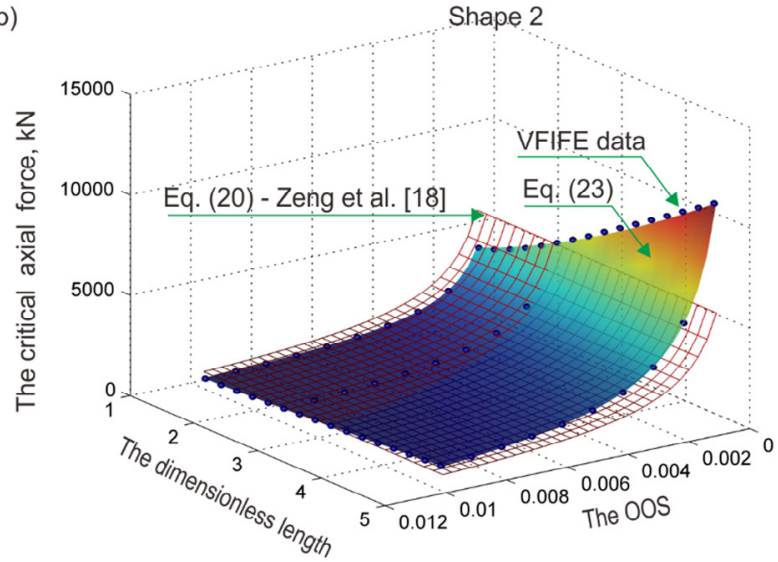

(c)

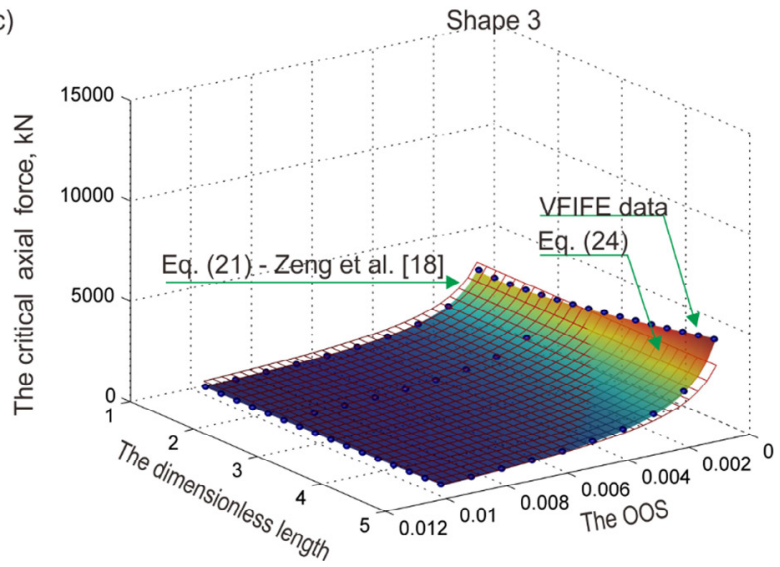

Fig. 12. Comparison between the approximation formulas and the VFIFE results of the critical axial force for the studied pipeline with (a) shape 1, (b) shape 2, and (c) shape 3.
Moreover, Fig. 10 shows that formulas of Zeng et al. [18] agree better with shape 1 and shape 2 than with shape 3 when $L=100 \mathrm{~m}$. The reason might be that the coefficient $a$ in Eq. (12) should change with imperfection shape while formulas of Zeng et al. [18] assumed that $a$ is a constant equal to 2 as shown in Eq. (13). Additionally, Fig. 11 shows that the effect of the imperfection length is the most dramatic for shape 1 and the least obvious for shape 3 .

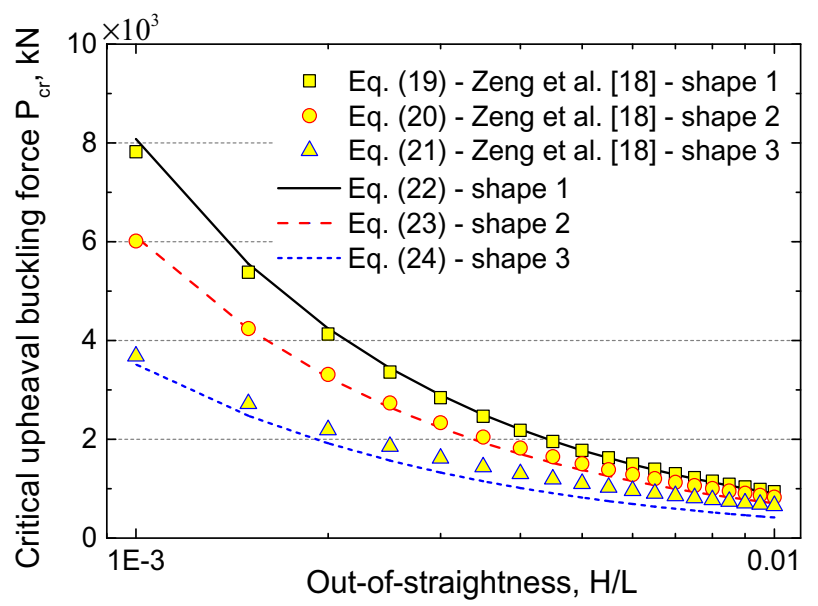

Fig. 13. Comparison between the proposed approximation formulas and the ones of Zeng et al. [18] when the dimensionless imperfection length is 2.4579 .

Table 4

Parameters of the pipes used in application simulations.

\begin{tabular}{|c|c|c|}
\hline \multirow[t]{2}{*}{ Property } & \multicolumn{2}{|l|}{ Value } \\
\hline & $\begin{array}{l}\text { Double-walled } \\
\text { natural gas pipe }\end{array}$ & $\begin{array}{l}\text { Single-walled } \\
\text { crude oil pipe }\end{array}$ \\
\hline $\begin{array}{l}\text { The outer diameter of the steel } \\
\text { pipe, } D(\mathrm{~mm})\end{array}$ & 522 & 385 \\
\hline $\begin{array}{l}\text { The thickness of the steel pipe } \\
\text { wall, } t(\mathrm{~mm})\end{array}$ & 14.3 & 12.0 \\
\hline $\begin{array}{l}\text { The thickness of the outer concrete } \\
\text { coating, } t_{o}(\mathrm{~mm})\end{array}$ & 40 & 0 \\
\hline The Young's modulus, $E(\mathrm{GPa})$ & 2.07 & 2.07 \\
\hline The Poisson's ratio, $v$ & 0.3 & 0.3 \\
\hline $\begin{array}{l}\text { The equivalent cross-sectional } \\
\text { moment of inertia, } I\left(\mathrm{~m}^{4}\right)\end{array}$ & $1.10 \times 10^{-3}$ & $2.22 \times 10^{-4}$ \\
\hline $\begin{array}{l}\text { The equivalent cross-sectional } \\
\text { area, } A\left(\mathrm{~m}^{2}\right)\end{array}$ & 0.0222 & 0.0136 \\
\hline $\begin{array}{l}\text { The density of internal flow, } \rho(\mathrm{kg} / \\
\left.\mathrm{m}^{3}\right)\end{array}$ & 149.0 & 800.0 \\
\hline \multirow{2}{*}{$\begin{array}{l}\text { The distribution load on pipelines, } \\
\qquad q(\mathrm{~N} / \mathrm{m})\end{array}$} & 1296.4 (Unburied) & 699.3 (Unburied) \\
\hline & 2587.9 (Buried) & 1651.8 (Buried) \\
\hline $\begin{array}{l}\text { The thermal expansion coefficient, } \\
C T E\left(/{ }^{\circ} \mathrm{C}\right)\end{array}$ & $1.17 \times 10^{-5}$ & $1.17 \times 10^{-5}$ \\
\hline
\end{tabular}

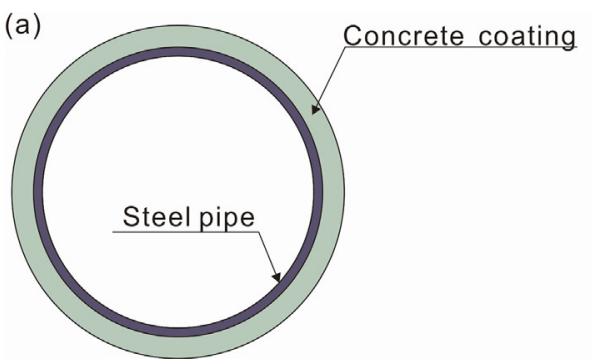

(b)

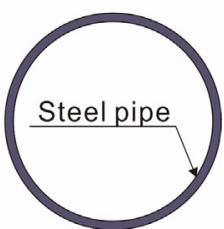

Fig. 14. Cross-sections of (a) the double-walled natural gas pipe, and (b) the singlewalled crude oil pipe. 


\subsection{Fitting formulas}

Multiply linear regression method is adopted to determine the coefficients $C_{0} \sim C_{5}$ in Eq. (17). The critical axial forces of 56 cases for each imperfection shape are used in the numerical fitting. The coefficients of determination for shape 1 , shape 2 and shape 3 are $99.99 \%, 99.97 \%$ and $99.93 \%$, respectively. Substitute the coefficients $C_{0} \sim C_{5}$ into Eq. (18), the approximation formulas of the critical axial forces are obtained and presented below.

For shape 1

$\bar{P}_{\text {cr1 }}=0.0958 \bar{L}^{2.0847+0.4948 \lg \bar{L}}\left(\frac{H}{L}\right)^{-1.0507-0.0302 \lg \left(\frac{H}{L}\right)-0.1192 \lg \bar{L}}$

For shape 2

$\bar{P}_{\text {cr2 }}=0.07 \bar{L}^{1.9873+0.5904 \lg \bar{L}}\left(\frac{H}{L}\right)^{-1.1152-0.0426 \lg \left(\frac{H}{L}\right)-0.0917 \lg \bar{L}}$

For shape 3

$\bar{P}_{\mathrm{cr} 3}=0.0347 \bar{L}^{1.7470+0.6794 \lg \bar{L}}\left(\frac{H}{L}\right)^{-1.2870-0.0729 \lg \left(\frac{H}{L}\right)-0.0091 \lg \bar{L}}$

Fig. 12 shows that the newly proposed approximation formulas agree well with the numerical data, whilst the formulas of Zeng et al. [18] diverge with the numerical results, especially when the dimensionless imperfection length is large and the oOS is small. For the pipeline studied in Zeng et al. [18] with imperfection length of $100 \mathrm{~m}$, the dimensionless imperfection length is equal to 2.4579 and the corresponding critical axial forces are shown in Fig. 13. It is shown that the newly proposed formulas generally agree with the ones of Zeng et al. [18] when the dimensionless imperfection is 2.4579. However, Fig. 12 shows that formulas of Zeng et al. [18] diverge with the numerical data and the newly proposed formulas, because they haven't included the size effect of the imperfection. This indicates that the newly proposed formulas are extending of the formulas of Zeng et al. [18], by considering the size effect or the influence of the dimensionless imperfection length.

The OOS is a destabilizing factor making the imperfect pipeline easier to buckle. Therefore, the critical axial forces increase with decreasing of the OOS. This is predicted by the approximation formulas in both this paper and Zeng et al. [18]. The dimensionless imperfection length $\bar{L}$ is a stabilizing factor, and the critical axial forces increase with $\bar{L}$. When an imperfection is relatively smaller, the critical force of upheaval buckling is smaller and the pipeline is more easily to have upheaval buckling. This effect is not predicted

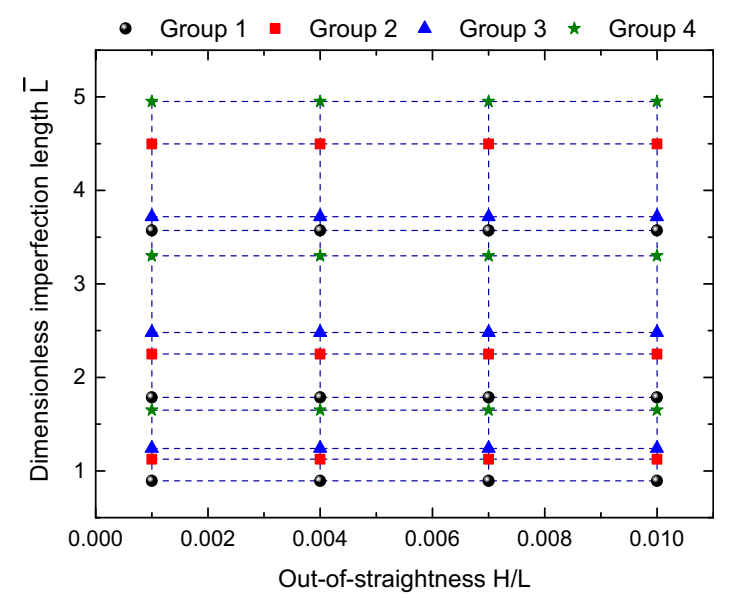

Fig. 15. OOS and dimensionless imperfection length of the application cases. by the formulas of Zeng et al. [18] but by the formulas proposed in this paper.

\subsection{Application and error analysis}

In this section, the proposed formulas are compared with results from simulations for pipelines with different crosssectional properties listed in Table 4. Cross-sections of the two pipes are shown in Fig. 14a and b respectively. One is a doublewalled natural gas pipe. The outer diameter and wall thickness of the inner steel pipe are $0.522 \mathrm{~m}$ and $14.3 \mathrm{~mm}$, respectively. Thickness of the outer concrete coating is $40 \mathrm{~mm}$. Another one is a single-walled crude oil pipe with outer diameter of $0.385 \mathrm{~m}$ and wall thickness of $12.0 \mathrm{~mm}$. Density of the natural gas and the crude oil are $149 \mathrm{~kg} / \mathrm{m}^{3}$ and $800 \mathrm{~kg} / \mathrm{m}^{3}$, respectively.

The unburied condition and the buried condition are considered. On the unburied condition, the pipelines are directly laid

(a)

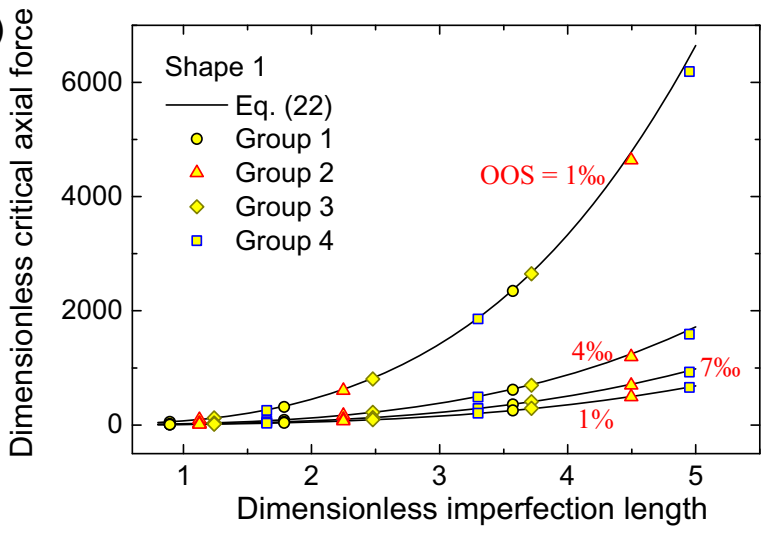

(b) $\stackrel{0}{0}$

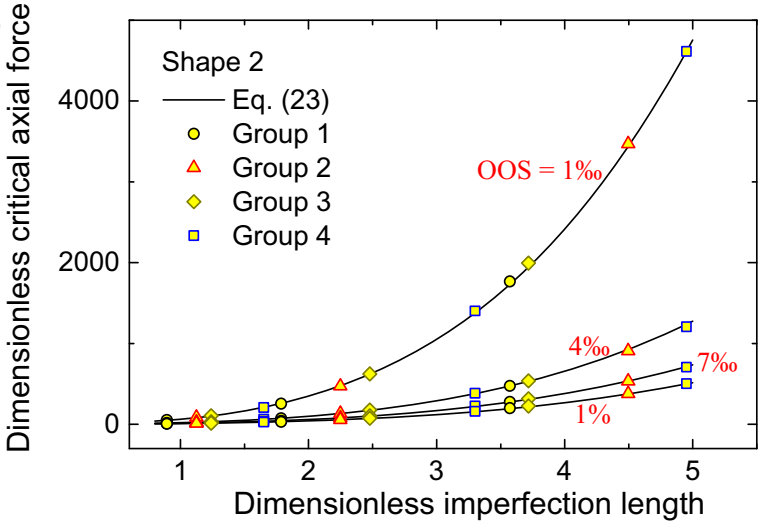

(c) $\stackrel{9}{0}$

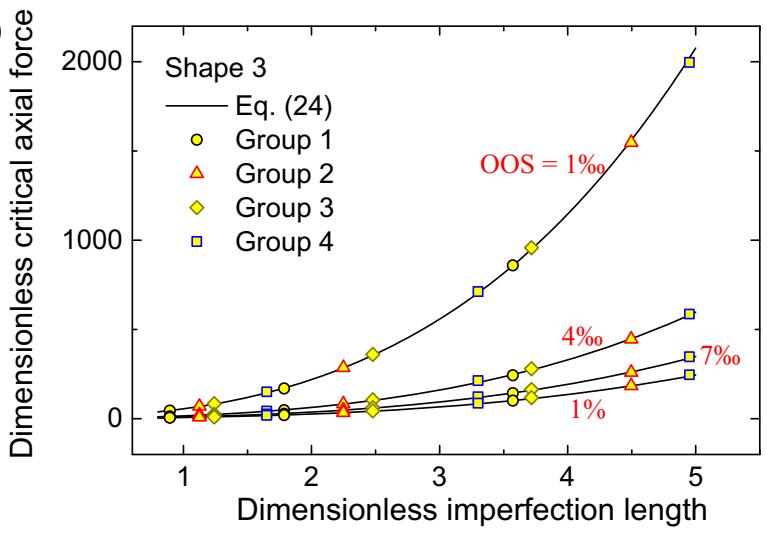

Fig. 16. Comparison between the VFIFE results and the approximation formulas: (a) shape 1 , (b) shape 2 , and (c) shape 3 . 
on the seabed and the submerged weight are $1296.4 \mathrm{kN} / \mathrm{m}$ and $699.3 \mathrm{kN} / \mathrm{m}$ for the doubled-walled natural gas pipeline and the single-walled crude oil pipeline, respectively. On the buried condition, the pipelines are assumed buried in $1.5 \mathrm{~m}$ of dense sand and the vertical distributed forces are $2587.9 \mathrm{kN} / \mathrm{m}$ and $1651.8 \mathrm{kN} / \mathrm{m}$ for the double-walled natural gas pipeline and the single-walled crude oil pipeline, respectively.

The application cases are divided into four groups: group 1, group 2, group 3 and group 4 . Group 1 and 2 correspond to the unburied and buried double-walled natural gas pipeline, respectively. Group 3 and 4 correspond to the unburied and buried single-walled crude oil pipeline, respectively. For each group, three values of imperfection length are considered and for each value of imperfection length, four values of the OOS are considered. Therefore, there are 48 application cases for each imperfection shape. The simulations are plotted as scatter points in Fig. 15. They are in the dimensionless scope of $\bar{H}=0.001-0.01$ and $\bar{L}=0.89-4.95$.

Fig. 16 illustrates that the VFIFE results agree well with the proposed formulas for pipelines with different cross-sectional properties, buried conditions and imperfection shapes. The dimensionless imperfection length is a parameter representing the combination effects of the imperfection length, the vertical distributed force and the cross-sectional properties. Therefore, results from different numerical groups reflect the same change pattern in the dimensionless form.

The critical axial forces of upheaval buckling are different for pipelines with different cross-sectional properties and buried conditions. For example, when the imperfection length is $100 \mathrm{~m}$, the imperfection height is $0.1 \mathrm{~m}$ and with imperfection shape 1 , the critical axial forces are $7225 \mathrm{kN}, 13,785 \mathrm{kN}, 3708 \mathrm{kN}$ and $8530 \mathrm{kN}$ for the unburied (buried) double-walled nature gas pipeline and the unburied (buried) single-walled crude oil pipeline, respectively. The corresponding values predicted with the formulas of Zeng et al. [18] are $9304 \mathrm{kN}, 14,750 \mathrm{kN}, 3616 \mathrm{kN}, 6414 \mathrm{kN}$, respectively. And the corresponding values (relative errors) predicted with the newly proposed formulas are $7329 \mathrm{kN}, 13,783 \mathrm{kN}$, $3657 \mathrm{kN}$, and $8379 \mathrm{kN}$, respectively. Relative errors between approximation formulas and the VFIFE results are defined as:

$e=\frac{P_{\mathrm{cr}}^{\mathrm{F}}-P_{\mathrm{cr}}^{\mathrm{V}}}{P_{\mathrm{cr}}^{\mathrm{V}}} \times 100 \%$

where $e$ is the relative error, $P_{\mathrm{cr}}^{\mathrm{F}}$ is the critical force of the approximation formulas and $P_{\mathrm{cr}}^{\mathrm{V}}$ is the critical force of the VFIFE simulations. The relative errors of the formulas of Zeng et al. [18] are $28.8 \%, 7.0 \%,-2.5 \%$ and $-24.8 \%$ for the unburied (buried) doublewalled nature gas pipeline and the unburied (buried) singlewalled crude oil pipeline, respectively. And the corresponding relative errors of the newly proposed formulas are $1.44 \%,-0.01 \%$, $-1.38 \%$, and $-1.77 \%$, respectively. The newly proposed formulas are more accurate.

For all the application cases of each imperfection shape, the relative errors for the proposed approximation formulas and the formulas of Zeng et al. [13] are listed in Tables 5-8, where $e_{1}$ is the relative error of the newly proposed formulas and $e_{2}$ is the relative errors of the formulas of Zeng et al. [18]. For all the application cases, the relative errors of the newly proposed formulas are proved within $\pm 5 \%$. In some situations, the relative errors of the formulas of Zeng et al. [18] are acceptable, whilst in some cases the relative errors can approach $81.04 \%$ (-49.24), 73.92\% (-47.66) and $72.27 \%$ ( -25.87 ), for the cases with shape 1 , shape 2 and shape 3 , respectively. The effect of the dimensionless imperfection length is proved

Table 5

Critical axial forces for the cases in group 1 (the double-walled natural gas pipeline in the unburied situation).

\begin{tabular}{|c|c|c|c|c|c|c|c|c|c|c|}
\hline \multirow[t]{2}{*}{$H$} & \multirow[t]{2}{*}{$L$} & \multicolumn{3}{|c|}{ Shape 1} & \multicolumn{3}{|c|}{ Shape 2} & \multicolumn{3}{|c|}{ Shape 3} \\
\hline & & $\overline{P_{\mathrm{cr}}^{\mathrm{V}}}$ & $e_{1}(\%)$ & $e_{2}(\%)$ & $\overline{P_{\mathrm{cr}}^{\mathrm{V}}}$ & $e_{1}(\%)$ & $e_{2}(\%)$ & $\overline{P_{\mathrm{cr}}^{\mathrm{V}}}$ & $e_{1}(\%)$ & $e_{2}(\%)$ \\
\hline 0.05 & 50 & 5139 & -2.08 & 81.04 & 4655 & -2.42 & 53.68 & 4117 & 0.89 & 6.47 \\
\hline 0.2 & 50 & 1522 & -2.61 & 70.39 & 1360 & -1.52 & 59.54 & 1198 & 0.55 & 29.46 \\
\hline 0.35 & 50 & 895 & -0.32 & 73.01 & 797 & 0.60 & 68.19 & 698 & 1.16 & 46.07 \\
\hline 0.5 & 50 & 633 & 1.54 & 76.10 & 567 & 1.35 & 73.92 & 499 & -0.37 & 56.39 \\
\hline 0.1 & 100 & 7225 & 1.44 & 28.77 & 5795 & 2.15 & 23.45 & 3849 & 1.52 & 13.89 \\
\hline 0.4 & 100 & 2041 & 0.65 & 27.06 & 1664 & 0.96 & 30.39 & 1093 & 3.29 & 41.89 \\
\hline 0.7 & 100 & 1201 & 0.90 & 28.93 & 974 & 1.67 & 37.62 & 639 & 3.40 & 59.56 \\
\hline 1 & 100 & 845 & 2.01 & 31.92 & 693 & 1.41 & 42.30 & 453 & 2.59 & 72.27 \\
\hline 0.2 & 200 & 13355 & -1.73 & -30.34 & 10054 & -1.84 & -28.85 & 4892 & -0.23 & -10.40 \\
\hline 0.8 & 200 & 3505 & -0.15 & -26.01 & 2698 & -0.09 & -19.58 & 1386 & 1.35 & 11.90 \\
\hline 1.4 & 200 & 2052 & -1.39 & -24.54 & 1579 & -0.92 & -15.11 & 815 & 0.72 & 25.10 \\
\hline 2 & 200 & 1450 & -2.00 & -23.12 & 1127 & -2.44 & -12.50 & 577 & -0.02 & 35.25 \\
\hline
\end{tabular}

Table 6

Critical axial forces for the cases in group 2 (the double-walled natural gas pipeline in the buried situation).

\begin{tabular}{|c|c|c|c|c|c|c|c|c|c|c|}
\hline \multirow[t]{2}{*}{$H$} & \multirow[t]{2}{*}{$L$} & \multicolumn{3}{|c|}{ Shape 1} & \multicolumn{3}{|c|}{ Shape 2} & \multicolumn{3}{|c|}{ Shape 3} \\
\hline & & $\overline{P_{\mathrm{cr}}^{\mathrm{V}}}$ & $e_{1}(\%)$ & $e_{2}(\%)$ & $\overline{P_{\mathrm{cr}}^{\mathrm{V}}}$ & $e_{1}(\%)$ & $e_{2}(\%)$ & $\overline{P_{\mathrm{cr}}^{\mathrm{V}}}$ & $e_{1}(\%)$ & $e_{2}(\%)$ \\
\hline 0.05 & 50 & 8698 & 1.58 & 69.58 & 7666 & -0.18 & 47.95 & 6343 & -1.42 & 9.56 \\
\hline 0.2 & 50 & 2619 & -2.25 & 56.99 & 2285 & -2.50 & 50.54 & 1864 & -2.84 & 31.91 \\
\hline 0.35 & 50 & 1540 & -0.61 & 59.41 & 1346 & -1.43 & 57.88 & 1095 & -3.10 & 47.62 \\
\hline 0.5 & 50 & 1096 & 0.18 & 61.25 & 944 & 0.41 & 65.62 & 768 & -2.75 & 61.10 \\
\hline 0.1 & 100 & 13785 & -0.01 & 7.00 & 10720 & 0.96 & 5.80 & 6505 & -0.64 & 6.83 \\
\hline 0.4 & 100 & 3805 & -0.14 & 8.06 & 3052 & -0.63 & 12.71 & 1879 & -0.74 & 30.85 \\
\hline 0.7 & 100 & 2244 & -0.77 & 9.40 & 1792 & -0.76 & 18.59 & 1102 & -1.00 & 46.68 \\
\hline 1 & 100 & 1587 & -0.63 & 11.36 & 1274 & -1.25 & 22.72 & 777 & -1.26 & 59.23 \\
\hline 0.2 & 200 & 26402 & 0.13 & -44.13 & 19742 & -0.80 & -42.55 & 8807 & 0.73 & -21.09 \\
\hline 0.8 & 200 & 6795 & 2.04 & -39.49 & 5172 & 2.12 & -33.49 & 2537 & 0.52 & -3.08 \\
\hline 1.4 & 200 & 3967 & 0.38 & -38.12 & 3031 & 0.62 & -29.89 & 1482 & 0.50 & 9.07 \\
\hline 2 & 200 & 2805 & -0.73 & -37.00 & 2149 & -0.60 & -27.25 & 1051 & -0.44 & 17.72 \\
\hline
\end{tabular}


Table 7

Critical axial forces for the cases in group 3 (the single-walled crude oil pipeline in the unburied situation).

\begin{tabular}{|c|c|c|c|c|c|c|c|c|c|c|}
\hline \multirow[t]{2}{*}{$\mathrm{H}$} & \multirow[t]{2}{*}{$\mathrm{L}$} & \multicolumn{3}{|c|}{ Shape 1} & \multicolumn{3}{|c|}{ Shape 2} & \multicolumn{3}{|c|}{ Shape 3} \\
\hline & & $\overline{\mathrm{P}_{\mathrm{cr}}^{\mathrm{V}}}$ & $\mathrm{e}_{1}(\%)$ & $\mathrm{e}_{2}(\%)$ & $\overline{\mathrm{P}_{\mathrm{cr}}^{\mathrm{V}}}$ & $\mathrm{e}_{1}(\%)$ & $\mathrm{e}_{2}(\%)$ & $\overline{\mathrm{P}_{\mathrm{cr}}^{\mathrm{V}}}$ & $\mathrm{e}_{1}(\%)$ & $\mathrm{e}_{2}(\%)$ \\
\hline 0.05 & 50 & 2239 & 1.70 & 61.55 & 1929 & 0.59 & 44.18 & 1547 & -2.14 & 10.16 \\
\hline 0.2 & 50 & 676 & -3.08 & 49.14 & 583 & -3.62 & 44.69 & 463 & -5.34 & 30.22 \\
\hline 0.35 & 50 & 397 & -1.61 & 51.64 & 343 & -2.64 & 51.93 & 269 & -4.57 & 47.35 \\
\hline 0.5 & 50 & 283 & -1.16 & 53.13 & 242 & -1.56 & 58.42 & 189 & -4.23 & 60.53 \\
\hline 0.1 & 100 & 3708 & -1.38 & -2.45 & 2859 & -0.62 & -2.72 & 1653 & -1.48 & 3.10 \\
\hline 0.4 & 100 & 1014 & -1.27 & -0.57 & 809 & -2.12 & 4.27 & 485 & -3.16 & 24.32 \\
\hline 0.7 & 100 & 598 & -2.18 & 0.67 & 478 & -3.06 & 9.02 & 286 & -3.96 & 38.59 \\
\hline 1 & 100 & 426 & -2.91 & 1.73 & 339 & -3.45 & 13.09 & 199 & -2.95 & 52.46 \\
\hline 0.15 & 150 & 5407 & -1.81 & -33.10 & 4070 & -2.19 & -31.67 & 1956 & -0.90 & -12.87 \\
\hline 0.6 & 150 & 1422 & -0.72 & -29.10 & 1099 & -1.28 & -23.25 & 572 & -2.49 & 5.41 \\
\hline 1.05 & 150 & 836 & -2.48 & -27.99 & 644 & -2.31 & -19.08 & 334 & -2.43 & 18.68 \\
\hline 1.5 & 150 & 598 & -4.33 & -27.53 & 459 & -3.73 & -16.48 & 240 & -4.58 & 26.42 \\
\hline
\end{tabular}

Table 8

Critical axial forces for the cases in group 4 (the single-walled crude oil pipeline in the buried situation).

\begin{tabular}{|c|c|c|c|c|c|c|c|c|c|c|}
\hline \multirow[t]{2}{*}{$\mathrm{H}$} & \multirow[t]{2}{*}{$\mathrm{L}$} & \multicolumn{3}{|c|}{ Shape 1} & \multicolumn{3}{|c|}{ Shape 2} & \multicolumn{3}{|c|}{ Shape 3} \\
\hline & & $\mathrm{P}_{\mathrm{cr}}^{\mathrm{V}}$ & $\mathrm{e}_{1}(\%)$ & $\mathrm{e}_{2}(\%)$ & $\mathrm{P}_{\mathrm{cr}}^{\mathrm{V}}$ & $\mathrm{e}_{1}(\%)$ & $\mathrm{e}_{2}(\%)$ & $\mathrm{P}_{\mathrm{cr}}^{\mathrm{V}}$ & $\mathrm{e}_{1}(\%)$ & $\mathrm{e}_{2}(\%)$ \\
\hline 0.05 & 50 & 4690 & 2.15 & 36.78 & 3827 & 2.18 & 28.89 & 2772 & -3.54 & 9.04 \\
\hline 0.2 & 50 & 1387 & -2.65 & 28.92 & 1163 & -4.16 & 28.64 & 805 & -3.98 & 32.84 \\
\hline 0.35 & 50 & 825 & -3.22 & 29.42 & 690 & -4.64 & 33.95 & 476 & -5.04 & 47.69 \\
\hline 0.5 & 50 & 586 & -2.95 & 31.16 & 483 & -3.04 & 40.78 & 335 & -5.07 & 60.63 \\
\hline 0.1 & 100 & 8530 & -1.77 & -24.79 & 6442 & -1.59 & -23.43 & 3274 & -1.23 & -7.68 \\
\hline 0.4 & 100 & 2252 & -0.22 & -20.60 & 1758 & -1.07 & -14.90 & 980 & -4.98 & 9.12 \\
\hline 0.7 & 100 & 1329 & -2.01 & -19.66 & 1039 & -2.68 & -11.04 & 566 & -3.89 & 24.21 \\
\hline 1 & 100 & 946 & -3.19 & -18.75 & 741 & -4.00 & -8.24 & 401 & -4.71 & 34.19 \\
\hline 0.15 & 150 & 12637 & 1.19 & -49.24 & 9424 & 0.03 & -47.66 & 4077 & 1.10 & -25.87 \\
\hline 0.6 & 150 & 3247 & 2.59 & -44.93 & 2463 & 2.68 & -39.26 & 1198 & -1.15 & -10.74 \\
\hline 1.05 & 150 & 1890 & 0.94 & -43.51 & 1442 & 1.05 & -35.91 & 709 & -2.46 & -0.84 \\
\hline 1.5 & 150 & 1343 & -0.84 & -42.77 & 1026 & -0.65 & -33.73 & 504 & -3.62 & 6.77 \\
\hline
\end{tabular}

significant in the studied cases and neglecting this effect could induce great errors for all the three imperfection shapes.

\section{Conclusion}

In this paper, the VFIFE method is used to study the critical axial forces of upheaval buckling for pipelines with initial imperfections. Accuracy of the VFIFE method is evaluated by comparing the results with conventional FEM. Results with different imperfection shapes and different values of imperfection height agree well with previous publications.

The effect of the imperfection length $L$ on the critical axial force is found dramatic even when the OOS is constant. This size effect is not considered in previous approximation formulas. To account for this effect, a new parameter named dimensionless imperfection length $\bar{L}$ is proposed. Meanwhile, the dimensionless critical axial force $\bar{P}_{\mathrm{cr}}$ is found dominated by the dimensionless imperfection length and the OOS.

Subsequently, an approximate formula covering the two parameters is derived, and coefficients in the formulas are fitted with numerical results. To account for the geometric nonlinearity of the initially imperfect pipeline, coefficients in the formulas are assumed to change with the OOS and the dimensionless imperfection length. The proposed approximation formulas are suggested more general and more accurate than the previous ones. In addition, they are applicable to pipelines with different crosssectional properties and buried conditions. Remarkably, relative errors of the formulas are proved within the range of $\pm 5 \%$ in the application scope of $\bar{H}=0.001-0.01, \bar{L}=0.89-4.95$.

Three typical imperfection shapes are considered in this paper. For a pipeline with an imperfection similar with the studied ones, the proposed formulas can be used to calculate or estimate the critical axial force of upheaval buckling quickly. While an imperfection shape is somewhat random in practical engineering and may be quite different with the studied ones. In this case, the proposed formulas is not applicable. Zhang and Duan [15] defined an imperfection shape parameter to express the differences of imperfection shapes, whilst they haven't considered the influence of the dimensionless imperfection length. Therefore, further efforts may be paid to include the imperfection shape parameter in the approximation formulas proposed in this study.

\section{Acknowledgments}

This research was financially supported by the Key Instrument Developing Project of CAS (No. ZDYZ2012-1-08-02), the National High-tech R\&D Program of China (No. 2006AA09Z301) and the National Natural Science Foundation of China (No. 11302235).

\section{References}

[1] Croll JG. A simplified model of upheaval thermal buckling of subsea pipelines. Thin Walled Struct 1997;29:59-78.

[2] da Costa AM, de Oliveira Cardoso C, dos Santos Amaral C, Andueza A. Soilstructure interaction of heated pipeline buried in soft clay. In: 2002 4th international pipeline conference. American Society of Mechanical Engineers; 2002. p. 457-66.

[3] Nazari A, Rajeev P, Sanjayan JG. Modelling of upheaval buckling of offshore pipeline buried in clay soil using genetic programming. Eng Struct 2015;101:306-17.

[4] Tvergaard V. On the localization of buckling patterns. J Appl Mech 1980;47:613-9.

[5] Yun H, Kyriakides S. Model for beam-mode buckling of buried pipelines. J Eng Mech 1985;111:235-53. 
[6] Richards D. The effect of imperfection shape on upheaval buckling behaviour. In: Advances in subsea pipeline engineering and technology. Springer; 1990. p. 51-66.

[7] Croll JG. A simplified analysis of imperfect thermally buckled subsea pipelines. Int J Offshore Polar Eng 1998;8:283-91.

[8] Maltby TC, Calladine CR. An investigation into upheaval buckling of buried pipelines-I. Experimental apparatus and some observations. Int J Mech Sci $1995 ; 37: 943-63$.

[9] Maltby TC, Calladine CR. An investigation into upheaval buckling of buried pipelines-II. Theory and analysis of experimental observations. Int J Mech Sci 1995;37:965-83.

[10] Taylor N, Tran V. Experimental and theoretical studies in subsea pipeline buckling. Mar Struct 1996;9:211-57.

[11] Taylor N, Tran V. Prop-imperfection subsea pipeline buckling. Mar Struct $1993 ; 6: 325-58$.

[12] Taylor N, Gan A. Refined modelling for the vertical buckling of submarine pipelines. J Constr Steel Res 1987;7:55-74.

[13] Taylor N, Gan AB. Submarine pipeline buckling-imperfection studies. Thin Walled Struct 1986:4:295-323.

[14] Karampour H, Albermani F, Gross J. On lateral and upheaval buckling of subsea pipelines. Eng Struct 2013;52:317-30.

[15] Zhang X, Duan M. Prediction of the upheaval buckling critical force for imperfect submarine pipelines. Ocean Eng 2015;109:330-43.

[16] Wang Y, Zhang X, Zhao Y, Chen H, Duan M, Estefen SF. Perturbation analysis for upheaval buckling of imperfect buried pipelines based on nonlinear pipe-soil interaction. Ocean Eng 2017;92-100.

[17] Palmer A, Ellinas C, Richards D, Guijt J. Design of submarine pipelines against upheaval buckling. In: Offshore technology conference: offshore technology conference; 1990. p. OTC 6335.

[18] Zeng X, Duan M, Che X. Critical upheaval buckling forces of imperfect pipelines. Appl Ocean Res 2014;45:33-9.

[19] Shih C, Wang YK, Ting EC. Fundamentals of a vector form intrinsic finite element: Part III. Convected material frame and examples. J Mech 2004;20:133-43.

[20] Ting EC, Shih C, Wang Y-K. Fundamentals of a vector form intrinsic finite element: Part II. plane solid elements. J Mech 2004;20:123-32.

[21] Ting EC, Shih C, Wang Y-K. Fundamentals of a vector form intrinsic finite element: Part I. basic procedure and a plane frame element. J Mech 2004;20:113-22.
[22] Yuan F, Li L, Guo Z, Wang L. Landslide impact on submarine pipelines: analytical and numerical analysis. J Eng Mech 2014;04014109.

[23] Xu L, Lin M. Integrate pipe-soil interaction model with the vector form intrinsic finite element method-nonlinear analysis of free-span. In: The 24th international ocean and polar engineering conference. Busan, Korea: International Society of Offshore and Polar Engineers; 2014. p. 72-9.

[24] Tian Y, Cassidy MJ. The challenge of numerically implementing numerous force-resultant models in the stability analysis of long on-bottom pipelines. Comput Geotech 2010;37:216-32.

[25] Youssef BS, Cassidy MJ, Tian Y. Application of statistical analysis techniques to pipeline on-bottom stability analysis. J Offshore Mech Arct Eng 2013;135:031701.

[26] Xu L, Lin M. Numerical modeling of the configuration of a long-distance freespanning submarine pipeline on an uneven seabed. Int J Offshore Polar Eng 2017;27:102-11.

[27] Liu J, Xu L, Lin M. Simulation of a buried pipeline crossing strike-slip fault based on vector form intrinsic finite element (VFIFE) method with Fiber element model. In: The 26th international ocean and polar engineering conference. Rhodes, Greece: International Society of Offshore and Polar Engineers; 2016. p. 977-83.

[28] Xu L, Lin M. Analysis of buried pipelines subjected to reverse fault motion using the vector form intrinsic finite element method. Soil Dyn Earthquake Eng 2017;93:61-83.

[29] Ting EC, Duan YF, Wu DY. Vector mechanics of structures (in Chinese). Beijing: Science Press; 2012.

[30] Lien KH, Chiou YJ, Wang RZ, Hsiao PA. Vector form intrinsic finite element analysis of nonlinear behavior of steel structures exposed to fire. Eng Struct 2010;32:80-92.

[31] Wang Z. Theory and application of thin shell element based on the vector form intrinsic finite element method (in Chinese). Zhejiang University; 2013.

[32] Zhu J, Attard MM, Kellermann DC. In-plane nonlinear localised lateral buckling of straight pipelines. Eng Struct 2015;103:37-52.

33] Tomes K, Nystrem PR, Damsleth P, Sortland LH. The behaviour of high pressure high temperature flowlines on very uneven seabed. In: The seventh international offshore and polar engineering conference: international society of offshore and polar engineers; 1997. p. 321-9.

[34] Tan OM. Dimensional analysis-with case studies in mechanics. Berlin Heidelberg: Springer; 2011. 